
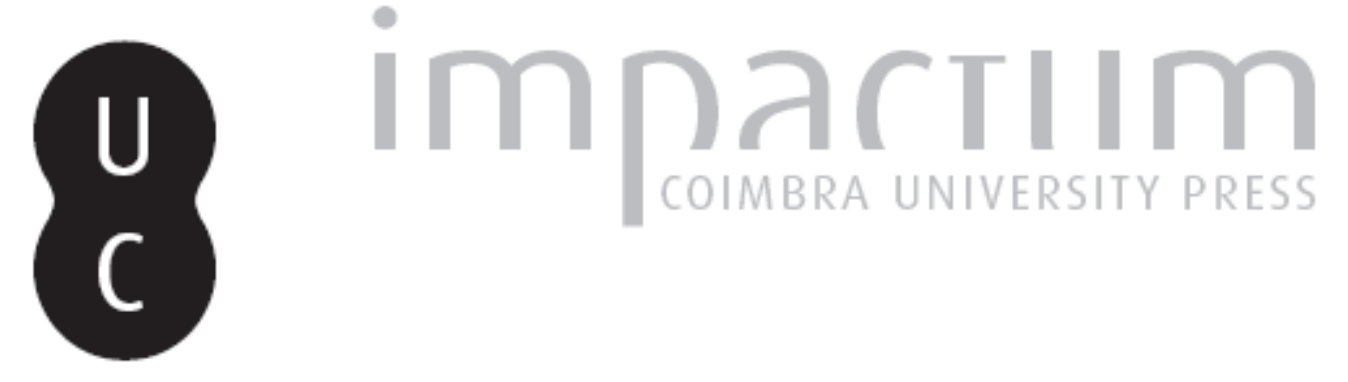

\title{
Livros recentes sobre a problemática dos riscos e das crises
}

Autor(es): Rebelo, Fernando

Publicado por: Associação Portuguesa de Riscos, Prevenção e Segurança

URL persistente:

URI:http://hdl.handle.net/10316.2/40138

DOI:

DOI:https://doi.org/10.14195/1647-7723_5_7

Accessed : $\quad$ 26-Apr-2023 08:26:01

A navegação consulta e descarregamento dos títulos inseridos nas Bibliotecas Digitais UC Digitalis, UC Pombalina e UC Impactum, pressupõem a aceitação plena e sem reservas dos Termos e Condições de Uso destas Bibliotecas Digitais, disponíveis em https://digitalis.uc.pt/pt-pt/termos.

Conforme exposto nos referidos Termos e Condições de Uso, o descarregamento de títulos de acesso restrito requer uma licença válida de autorização devendo o utilizador aceder ao(s) documento(s) a partir de um endereço de IP da instituição detentora da supramencionada licença.

Ao utilizador é apenas permitido o descarregamento para uso pessoal, pelo que o emprego do(s) título(s) descarregado(s) para outro fim, designadamente comercial, carece de autorização do respetivo autor ou editor da obra.

Na medida em que todas as obras da UC Digitalis se encontram protegidas pelo Código do Direito de Autor e Direitos Conexos e demais legislação aplicável, toda a cópia, parcial ou total, deste documento, nos casos em que é legalmente admitida, deverá conter ou fazer-se acompanhar por este aviso.

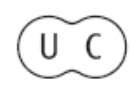




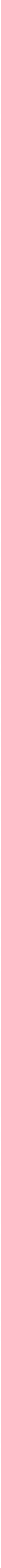




\section{Doutoramento em Geografia Física dedicado aos riscos geomorfológicos}

\section{Fernando Rebelo}

No dia 27 de Janeiro de 1998, realizou-se, em Lisboa, aquele que pode considerar-se o primeiro Doutoramento em Geografia Física dedicado aos estudos de riscos naturais no nosso país.

Movimentos de Vertente e Perigosidade Geomorfológica na Região a Norte de Lisboa é o título da tese apresentada por José Luís Zêzere para o seu Doutoramento pela Universidade de Lisboa. Na sua forma actual, policopiada, apresenta 575 páginas, muitas delas ilustradas com belas fotografias e bons mapas a cores, e ainda 3 mapas geomorfológicos de pormenor, extra-texto. Trata-se de um trabalho particularmente bem estruturado, iniciando-se com uma pequena "Introdução" (6 páginas) e terminando com um "Resumo e principais conclusões" (12 páginas). Pelo meio ficam dez capítulos - "O quadro geomorfológico" "Classificação e características dos movimentos de vertente", "Metodologia e técnicas de estudo", "Tipologia e dinâmica dos movimentos de vertente na região a Norte de Lisboa: exemplificação monográfica", "Papel da erosão lateral dos cursos de água e das acções antrópicas na actividade dos movimentos de vertente na região a Norte de Lisboa", "A avaliação da estabilidade das vertentes e a determinação dos parâmetros físicos dos terrenos por análise inversa", "Análise estatística dos movimentos de vertente nas áreas-amostra", "Estudo comparativo da tipologia, morfometria e factores condicionantes dos movimentos de vertente nas áreas-amostra", "A precipitação como factor desencadeante dos movimentos de vertente" e, finalmente, "A avaliação da perigosidade geomorfológica". Depois das conclusões segue-se uma "Bibliografia" muito completa, em especial no que respeita a movimentos de vertente.

Torna-se clara a opção de J.L. ZÊZERE pela palavra inglesa "hazard", que traduziu, à semelhança de espanhóis e italianos por "perigosidade". Sendo o "risco" o somatóriode "hazard" (o "aléas" dos franceses) com "vulnerabilidade", verifica-se que o Autor não quereria introduzir o homem e as suas realizações no trabalho que elaborou. Todavia, num espaço como o que escolheu, tal era completamente impossível deslizamentos de variados tipos, desabamentos equedas de blocos, estudados como "crises" ou, melhor, como "manifestações da crise"(1), afectaram directa ou indirectamente o Homem, como o próprio Autor mostra em fotografias ou cartogramas de pormenor. Por outro lado, terá sido, por vezes, o próprio homem o factor essencial no desencadear de algumas dessas "crises".

O estudo é, portanto, bem mais do que o seu título anuncia. Trata de "hazards", claro, mas baseia-se muito em análise de casos concretos de manifestações de risco e não lhe teria ficado mal assumi-lo no título do trabalho, mesmo que tal implicasse, em consciência, aprofundar um pouco mais a parte final.

Todo o espaço estudado é, infelizmente para os habitantes, muito rico em riscos geomorfológicos e o Autor mostra-o claramente. Além disso, os mapas geomorfológicos de pormenor das áreas-amostra (Calhandriz, Lousa, Pinheiro de Loures, Fanhões e Trancão) são de uma riqueza notável mostrando a hidrografia, a litologia do substracto, a estrutura e as formas ligadas à estrutura, as formas e as formações fluviais, as formas e as formações de vertente e interflúvio, as formas ligadas à actividade humana e, naturalmente, numa tese como esta, a dinâmica das vertentes com uma distinção importante quanto ao grau de actividade dos fenómenos identificados activos, dormentes e estabilizados.

Com o presente trabalho de J. L. ZÊZERE, a bibliografia sobre riscos, em geral, e sobre riscos geomorfológicos, em particular, começa também a ganhar importância no nosso país; aguarda-se, por isso, com muito interesse, a sua rápida publicação.

(1)L. FAUGÈrRES (1990), "La dimension des faits et la théorie du risque". Le Risque et la Crise”, Malta, Foundation for International Studies, 1990, p. $31-60$.

\section{Livros recentes sobre a problemática dos riscos e das crises}

\section{Fernando Rebelo}

1. Com uma primeira edição datada de 1993, mas jáesgotada, L'Homme et l'Environnement, de YVETTE VEYRET e PIERRE PECH (Paris, PUF, Collection Premier Cycle, 1997, 2e édition corrigée, 423 p.) veio de novo para os escaparates das livrarias no passado mês de Julho de 1997.
Depois de uma Introdução naturalmente dedicada à evolução das relações entre o homem e o ambiente e de uma primeira parte dedicada aos recursos, renováveis e não renováveis, os riscos aparecem em força na segunda e na terceira partes (respectivamente, "Contraintes et risques: risques naturels, risques 
induits par les activités humaines" e "L'homme et l'environnement: des relations différentes dans les pays riches et dans les pays en développement").

O início da segunda parte do livro é marcado pela questão das definições das palavras que mais irão ser utilizadas a seguir - "limitação", "constrangimentos", "aléas" ou "hazard" e "riscos" são as que mais preocupam os Autores. Logo de seguida, são tratados os "constrangimentos, 'aléas' e riscos climáticos", não se esquecendo uma importante referência ao tão falado fenómeno do "El Niño". Os "constrangimentos e riscos ligados à litosfera" correspondem a um capítulo, que, naturalmente, começa pelo "aléas" e risco vulcânico, bem como pelos sismos, mas trata igualmente de diversos tipos de movimentos de "terrenos". Outro capítulo é dedicado à hidrosfera, logo aos "constrangimentos e riscos ligados à água" e a variedade de casos apresentados é grande, desde problemas relacionados com a neve até problemas de inundações; a qualidade da água também não é esquecida; do mesmo modo é dada grande importância à "interface terra-mar" sendo vários os exemplos apresentados de riscos e de gestão de riscos em diferentes litorais. "A modificação dos cobertos vegetais e suas consequências" constitui um outro capítulo, particularmente importante quando trata da erosão dos solos e da degradação biológica.

A terceira parte deste livro confronta a problemática da gestão dos riscos nos países ricos e nos países em desenvolvimento. Assim, "os riscos ligados às actividades humanas" são salientados através de numerosos exemplos em que se destacam os factores antrópicos da erosão dos solos, mas não negligenciando, todavis, os "constrangimentos e riscos em meio

2. ADELIN VILLEVIEILLE é o Autor do livro Les risques naturels en Méditerranée. Situation et perspectives (Paris, Economica, Les Fascicules du Plan Bleu, 10, 1997, 160 p.), "publicado sob a égide do Programa das Nações Unidas para o ambiente no quadro do Plano de Acção para o Mediterrâneo (PAM). Diga-se desde já que Portugal, apesar da sua cultura e dos seus aspectos físicos tipicamente mediterrâneos, não se insere neste plano por não ser um país com costas no Mar Mediterrâneo.

OPrefácio deste livro é assinado por Michel Batisse, Presidente do Centro de Actividades Regionais do Plano Azul para o Mediterrâneo (Sophia-Antipolis, França) e dá uma ideia do que é o referido Plano de Acção, do que são os fascículos do Plano Azul e, ainda, do interesse em estudar os riscos nesta área do globo.

Exemplos concretos de manifestação de riscos nos países do Mediterrâneo iniciam a Introdução que apresenta, também, um pouco da teoria do risco - o urbano" igualmente com a apresentação de numerosos e variados exemplos desde os casos de abatimentos e deslizamentos até às questões relacionadas com o clima urbano e com as inundações. Falando-se em países ricos eram naturalmente de esperar algumas palavras sobre legislação ambiental, tal como referência a normas de gestão de riscos, e os autores não se esqueceram de dar alguns exemplos franceses. Completamente diferente foi o tratamento dado à problemática dos riscos nos países ditos em desenvolvimento: em primeiro lugar salientam-se os números elevadíssimos de perdas humanas quando do desencadeamento de crises como terramotos ou inundações, fala-se de doenças várias e das suas consequências, mostrando-se com facilidade as razões para tão grandes tragédias. "Algumas tentativas de protecção dos ecossistemas e dos recursos" aparecem como casos relativamente raros e quanto às grandes obras públicas pergunta-se se elas serão "remédios para os disfuncionamentos das relações homem-meio" - apresentam-se casos de grandes barragens e mostra-se que, por vezes, elas trouxeram novos problemas talvez não menos graves do que os que pretenderam resolver.

Da conclusão geral deste livro, uma frase, entre muitas outras, nos pareceu dever merecer atenção especial - "o homem não pode continuar a brincar aos aprendizes de feiticeiros, considerando muitas vezes que a sua tecnologia e as suas aquisições científicas lhe permitirão pôr fim a todos as disfunções que provoca ou que provocou na natureza" (p.404). $\mathrm{Na}$ verdade, o conhecimento geográfico tem-nos mostrado que as obras humanas, mesmo quando se nos afiguram perfeitas e definitivas, nunca o são -acabam por ser pequenos remendos no contexto da evolução natural do nosso planeta.

"aléa" físico (aquilo a que alguns chamam "perigosidade" e que o Autor define como "probabilidade de ocorrência de um acontecimento perigoso"), a vulnerabilidade humana e as estratégias (numa perspectiva de protecção civil - compreender para prever, prever para dominar).

O primeiro capítulo, "Presença do risco no Mediterrâneo", começa por um rápida resenha histórica dos "riscos mediterrâneos" referindo-se a catástrofes que marcaram profundamente a memória dos povos destas regiões - o "Dilúvio" bíblico, a catástrofe de Santorini, a erupção do Vesúvio em $79 \mathrm{dC}$ e o terramoto de Lisboa de 1755, entre outros. Curiosamente, $\operatorname{logo}$ aqui, começa a não se perceber por que motivo Portugal está fora deste grupo de países todos os riscos do Mediterrâneo são riscos em Portugal. Aliás, na figura 1, "Os tremores de terra catastróficos", Portugal está, infelizmente para nós, bem representado. Todavia, nos quadros 1 ("As grandes catástrofes sísmicas no Mediterrâneo no século XX") e 2 
("Inundações catastróficas no Mediterrâneo no século XX”) Portugal já não aparece, apesar de o critério do Autor não se ficar exclusivamente pelo Mediterrâneo, uma vez que coloca, no primeiro, o terramoto de Agadir, cidade-praia de Marrocos, situada no Atlântico, com uma longitude igual à de muitos locais do nosso país...Pelo mesmo critério, Lisboa devia ter sido incluída nas inundações catastróficas (quadro 2), pelo menos com o caso de 1967.

Neste primeiro capítulo ainda se trata da percepção do risco no Mediterrâneo e das tendências para o futuro perante factos como a concentração urbana ou as mudanças ambientais, entre outros.

O segundo capítulo ("Problemática dos riscos mediterrâneos") começa por analisaros riscos tectónicos no Mediterrâneo, ou seja, os que se relacionam com sismos e vulcões. Casos concretos, como os sismos de Skopje e do Cairo, são expostos; as referências a casos de erupções vulcânicas na área é menos desenvolvida. Segue-se aquele a que o Autor chama o "risco hidrometeorológico" (inundações e deslizamentos de terreno), onde também são dados alguns exemplos - destaca-se o caso de Nîmes (no mínimo $300 \mathrm{~mm}$ de chuva em 6 horas no dia 3 de Outubro de 1988, 10 mortos) por ter sido um dos melhor estudados. Seguem-se os riscos de deslizamento de terrenos e as avalanches. O capítulo culmina com o risco climático no Mediterrâneo, isto é, secura e fogos florestais -

3. La prévention des risques naturels. Rapport d'évaluation é o título de um livro da responsabilidade do "Comité interministériel de l'évaluation des politiques publiques" e do "Commissariat général du Plan" de França (Paris, La Documentation Française, 1997, 702 p.), rico de informação seja sobre casos concretos de manifestação de riscos, seja sobre legislação, seja ainda sobre a definição científica dos diferentes riscos naturais. Como se diz a abrir (p. 3), trata-se de um Relatório da instância de avaliação presidida por PAUL-HENRI BOURRELIER, que assina um dos prefácios (p. 7-10), e que teve por relatores GUY DENEUFBOURG, JEAN GRASSIN, PHILIPPE HUET, BERNADETTE DE VANSSAY e JEAN-DANIEL VAZELLE.

A Introdução deste grosso volume intitula-se "Objecto e método de avaliação" e, naturalmente, preocupa-se com algumas definições. Destaquemos as duas que mais discussões têm originado quando se fala em riscos - "aléa" natural e risco natural. Para os Autores deste livro, "aléa" natural é "um acontecimento que tem por origem um fenómeno 'natural', por oposição a um acontecimento provocado por uma acção humana. É, portanto, um acontecimento de probabilidade não nula que tem a sua origem e se desenvolve inicialmente num meio natural (ar, solo, água)" Quanto ao risco natural será, para os Autores, uma parte teórica sobre a génese e a variabilidade do clima mediterrâneo (com uma figura intitulada "Duração da estação seca" onde Portugal é contemplado) e referências a pragas de gafanhotos e a áreas de incêndios florestais. Para todos os riscos referidos há sempre algumas palavras sobre a sua previsão e prevenção.

O terceiro capítulo intitula-se "Estratégia mediterrânea contra os riscos naturais". Uma das primeiras frases é a célebre "compreender para prever e prever para dominar"; a partir daí o Autor preocupa-se com os recursos humanos, logo, com a vida associativa e a defesa civil, não esquecendo a educação escolar e post-escolar. Seguem-se referências às técnicas de luta contra os riscos e, finalmente, à gestão da crise.

"Chaves para o futuro no Mediterrâneo" é o título do quarto capítulo. É uma espécie de conclusão que gira em torno da explicação de um organigrama em que se salientam a antecipação, a investigação e a cooperação. Dão-se algumas pistas para a investigação, fala-se da cooperação internacional no Mediterrâneo apresentando-se um número elevado de instituições intergovernamentais e não governamentais que já se encontram no terreno. Lança-se mesmo a ideia de um Observatório para as catástrofes naturais no Mediterrâneo.

Em anexo, vem uma curta bibliografia com muitas referências a trabalhos elaborados ou patrocinados pela UNESCO.

"um acontecimento causador de prejuizos, dotado de uma certa probabilidade, consequência de 'aléa' natural ocorrendo num meio vulnerável. $\mathrm{O}$ risco resulta, portanto, da conjunção do 'aléa' e de um 'enjeu', sendo a vulnerabilidade a medida dos prejuizos de toda a ordem relacionados com a intensidade do 'aléa'. A esta definição técnica do risco deve ser associada a noção de aceitabilidade para aí integrar a sua componente social" (p. 22). O principal problema que se nos põe é o da tradução exacta de "aléa" e de "enjeu"; "aléa" é, evidentemente o "hazard" anglosaxónico, mas em português nem acaso, nem sorte, nem eventualidade, as palavras que lhe correspondem à letra nos dicionários, ajudam pouco para a sua compreensão; é bem claro, todavia, que perigosidade, como dizem autores italianos e espanhóis, também nãocorrespondeà ideia de base. Será mesmo necessário traduzir palavras-ideias como estas? "Enjeu", neste contexto, é sem dúvida menos importante, mas também não faz sentido traduzi-la por entrada ou por parada... Aqui, o "enjeu" é, na prática, a vulnerabilidade. Pessoalmente não me choca traduzir "aléa" ou "hazard" por risco, subentendendo-o em sentido restrito.

Oprimeirocapítulo deste livro-relatórioé dedicado aos riscos naturais e aos meios de os prevenir. Logicamente os exemplos das crises que estiveram por trás de todos estes trabalhos são franceses - 
inundações, fogos de florestas, avalanches, movimentos de vertentes aparecem por vezes com análises pormenorizadas; para alguns casos dão-se igualmente indicações sobre obras de protecção que foram sendo feitas através da história para reduzir os riscos.

O segundo capítulo vai mais longe, como se pode ler no título "A prevenção dos riscos naturais no mundo: comparação, cooperação". Os números cada vez mais elevados de ocorrências são salientados desde logo com gráficos e quadros e alguns casos especiais são destacados, como "o risco de ciclones nos Estados Unidos" (p. 72). A importância das companhias de seguros nas acções de prevenção é igualmente destacada.

"Avaliação do dispositivo: legislação, organização, orçamento" é o título do terceiro capítulo. De novo, é a França que está em análise - leis antigas e recentes relacionadas com a prevenção dos riscos, competências ministeriais, meios, organizações, sociedade civil, etc. Ao longo de todo este capítulo, os Autores não se limitam a apresentar o que existe, mas, sempre que consideram importante, fazem apreciações críticas no sentido de melhorar todas as componentes da prevenção; mesmo no respeitante aos orçamentos que lhe têm sido destinados, a análise crítica está bem presente...

O quarto capítulo intitula-se "Indemnização e sanção: seguro e direito das catástrofes naturais" e anda à volta de uma questão desde início enunciada - "as condições da reparação dos prejuizos permitida pela indemnização e pelas ajudas, e as acções em justiça instauram uma regulação positiva? Isto é, contribuem para evitar o regresso de acontecimentos semelhantes?' (p. 171). A análise feita neste capítulo conduz a diversas sugestões que são dirigidas tanto às companhias de seguros como ao poder judiciário.

A avaliação do início da utilização dos instrumentos técnicos da previsão é o tema tratado no quinto capítulo. Deste modo, é desde logo dada grande importância à cartografia dos riscos ("aléas") - falase, pois, da cartografia da localização provável de avalanches, de inundações, de incêndios de florestas, de movimentos de terrenos, de sismos e de vulcanismo. Mas também se analisam casos concretos de manifestação de crises, como o célebre caso das inundações do Sena em 1910 (p. 210), inundações que tanto afectaram Paris e que, recentemente estiveram na origem de um belo trabalho, muito ilustrado, de MARC AMBROISE-RENDU (1910-Paris Inondé, Paris, Editions Hervas, 1997, 112 p.). Neste capítulo trata-se também dos Planos de Exposição aos Riscos, dos Planos de Ocupação dos Solos, em resumo, tratase bastante de toda a problemática urbanística relacionada com os riscos e analisam-se exemplos concretos de actuações post-catástrofe, como é o caso da "prevenção em Nîmes depois da catástrofe de 3 de Outubro de 1988" (p. 228), e descrevem-se redes de vigilância para os diferentes tipos de riscos ("aléas").

O capítulo sexto intitula-se "Resultados, valores e finalidades da prevenção". Estão aqui em causa a segurança das pessoas e os prejuizos materiais; por isso são amplamente discutidos, sem todavia se deixar de discutir a escala mais vasta em que tudo isso se integra - o ordenamento do território.

"Conclusões e propostas" é o lógico encerramento do trabalho. São dezassseis as propostas deste relatório. As sete primeiras dizem respeito à prevenção dos acidentes "desenvolvendo a informação, a comunicação, a participação e a responsabilidade" - "formar imediatamente após cada catástrofe um grupo local de propostas", "criar uma Agência de análise de acidentes, independente", "estabelecer as contas anuais dos riscos naturais", "reforçar a peritageme as condições do seu exercício", "declarar a vulnerabilidade dos terrenos e obras por referência a normas e aprovar os dispositivos de segurança", "fazer participar os seguros na gestão global dos riscos, em particular pelo ajuste de prémios e franquias" e "desenvolver uma lógica de responsabilidade e abrir o debate público". As seis seguintes têm a ver com a mobilização dos esforços de todos sobre programas reordenados "rever a concepção, o equipamento e a gestão dos dispositivos de vigilância e de alerta", "tomar em conta os riscos no ordenamento do território", "realizar em 10 anos a cobertura a 1:25000 de todas as zonas de riscos pelos PPR (Planos de Prevenção de Riscos) e adaptar os POS (Planos de Ocupação de Solos) correspondentes", "reenquadrar e dinamizar os programas de manutenção dos meios e das obras de protecção", "iniciar programas prioritários de prevenção nas comunidades gravemente ameaçadas" e "desenvolver programas de investigação aplicada". Finalmente as três últimas propostas correspondem a "melhor organizar a contribuição dos três grupos de actores (Estado, colectividades, sociedade civil)" - "criar as condições próprias para incitar os actores potenciais a associar-se à prevenção", "desenvolver as formas comuns de acção das colectividades territoriais" e "modernizar o Estado" (p. 331-332). Será que todas estas propostas não poderiam aplicar-se igualmente ao caso português? Ao ler-se a pormenorização de cada uma delas, a ideia que fica é a de que salvaguardadas as devidas proporções, adaptadas determinadas disposições, a maior parte das propostas servem perfeitamente para o nosso país.

Terminado o relatório, o livro continua por mais umas trezentas páginas - anexos, muitos anexos, alguns com documentos, com casos concretos e até com alguma bibliografia específica. É, sem dúvida, um livro importante para quem se preocupa com a temática dos riscos e das crises. 
4. A erupção vulcânica de 1995 na Ilha do Fogo, Cabo Verde (Lisboa, Instituto de Investigação Científica Tropical, 1997, 421 p.) é o título de um livro que analisa a manifestação de uma crise de vulcanismo com um pormenor verdadeiramente excepcional. Trata-se da publicação das comunicações apresentadas num Simpósio Internacional efectuado em Lisboa, na Fundação Calouste Gulbenkian, de 23 a 25 de Setembro de 1996 e que permitiu dar uma visão científica muito profunda de tudo o que se relacionou com aquela erupção, desde os sismos que a antecederam ou que lhe foram simultâneos até às consequências ambientais que dela advieram.

Oito comunicações relacionam-se com o "enquadramento geotectónico". Duas delas referem-se concretamente aos sismos verificados, enquanto as outras dão as necessárias bases explicativas para a crise. A "caracterização da erupção"é dada por nove comunicações, uma das quais com aspectos descritivos, referindo-se à sua cronologia, as outras aprofundando diversos pormenores científicos das suas lavas ou simples incrustações. Finalmente, os "impactos da erupção" permitiram a diversos autores, em treze comunicações, tratarem de assuntos tão diversos como o controle das escoadas, a análise dos diferentes riscos, inclusivamente dos riscos para a saúde pública, as influências das erupções nas temperaturas do ar, os impactos sócio-económicos, a protecção civil, etc.

Como primeiros Autores das 30 comunicações agora publicadas encontram-se nomes como os de L. MATIAS, S. HELENO DA SILVA (duas), J. L. PEREIRA, A. BRUM DA SILVEIRA (duas), J. L. GASPAR, J. OSÓRIO, F. C. TORRES (duas), N. WALLENSTEIN, J. MADEIRA, L. C. SILVA, J.M. MUNHÁ, M. O. FIGUEIREDO (três), F. LE GUERN (duas), F. LAGOSCOSTA,L. QUENTAL, H.TAZZIEF, T. FERREIRA, E. CORREIA, L. A. BUGALHO, R. L. BARBER, J. CORREIA e F. MONTEIRO. Umdos nomes que aparece ligado a mais comunicações (sete)é o do geólogo caboverdiano A. MOTA GOMES, que assina duas delas como primeiro Autor.

Deste volume fazem parte ainda os discursos da sessão de abertura do Simpósio, as homenagens prestadas a Orlando Ribeiro (não esqueçamos o seu trabalho intitulado A Ilha do Fogo e as suas erupções, Lisboa, 1954, com uma segunda edição em 1960), a Torre de Assunção e a Frederico Machado, bem como os resumos de três conferências solicitadas, respectivamente, a António Ribeiro, J. E. Guest e A. Hirn. O livro termina com 12 interessantes fotografias a cores de aspectos diversos da erupção de 1995.

\section{Alguns vulcōes da Itha de S. Miguel, de Victor Hugo Forjaz*}

\section{Fernando Rebelo}

Editado em Ponta Delgada, em 1997, pelo Observatório Vulcanológico e Geotérmico dos Açores, este livro começa por dar ao leitor alguma informação histórica e geográfica sobre S. Miguel; destaquemos que, do ponto de vista geomorfológico, divide a ilha em 7 "conjuntos paisagísticos", a saber, Maciço das Sete Cidades, Plataforma dos Picos, Maciço da Lagoa do Fogo, Achada Congro-Furnas, Maciço das Furnas, Achada dos Boiões (Graminhais) e Maciço da Povoação-Nordeste.

O "historial geológico" dailha de S. Miguel começa por ser apresentado através daquilo a que o Autor chama "estudos geológicos clássicos". Gaspar Frutuoso (1522-1591) aparece como "o primeiro dos nossos vulcanólogos" na medida em que, sendo bom observadore contemporâneo de erupções, deixou, nas Saudades da Terra, escritos importantes para a sua época sobre a geologia da ilha. Vários Autores do século XIX são, igualmente, referidos, alguns dos quais escreveram sobre as águas minerais. Referências breves a diversos trabalhos da primeira metade do século XX, um

VICTOR HUGO FORJAZ, Alguns Vulcōes da Il ha de S. Miguel, l Parte, Ponta Delgada, Observatório Vulcanológico e Geotérmico dos Açores, 1997,160 p. certo destaque para os de G. Zbyszewski e de F. Machado já de meados dos anos 50 e curtas referências a numerosos trabalhos publicados desde 1970 completam esse "historial".

O maior capítulo deste livro é o que se intitula "Vulcanoestratigrafia". Inicia-se com a legenda da carta geológica de S. Miguel, publicada em 1959, e com a da carta vulcanológica de 1976, ambas a 1:50000, culminando com a vulcanoestratigrafia que o Autor propõe para uma carta vulcanológica a 1:25000. A partir daí, a explicação da estratigrafia é feita pormenorizadamente para cada uma das áreas que correspondem a diferentes fases de formação da ilha - área do Nordeste (a mais antiga, do Pliocénico e Plistocénico superior), área da Povoação, área das Furnas, área das Sete Cidades, área do Fogo, área dos Picos e erupções históricas. Fica, portanto, claramente expressa a formação da ilha a partir de duas ilhas "a ilha de S. Miguel (somatório dos territórios do Nordeste com os da Povoação e os das Furnas) separada por um longo canal (tal como hoje Faial e S. Jorge) da ilha das Sete Cidades" (p. 116).

É precisamente na parte final do livro, e antes de falar nos recursos naturais, que o Autor nos faz 